\title{
Physical and mechanical properties of raphia palm kernel at different moisture contents
}

\author{
${ }^{1}$ Dauda, S.M., ${ }^{1}$ Ismail, F., ${ }^{1}$ Balami, A.A, ${ }^{1}$ Aliyu, M., ${ }^{1}$ Mohammed, I.S. and ${ }^{2}$ Ahmad, D. \\ ${ }^{1}$ Agricultural and Bioresources Engineering Department, Federal University of Technology, PMB 65, \\ Minna Niger State, Nigeria \\ ${ }^{2}$ Department of Biological and Agricultural Engineering, Faculty of Engineering, University Putra \\ Malaysia, 43400 UPM Serdang, Selangor, Malaysia
}

\begin{abstract}
Article history:
Received in revised form: 3

November 2018

Available Online: 27

November 2018

Keywords:

Raphia palm,

Moisture content,

Mechanical properties,

Physical properties.
\end{abstract}

Received: 22 September 2018

Accepted: 13 November 2018

\section{DOI:}

https://doi.org/10.26656/fr.2017.3(4).141

\begin{abstract}
Raphia palm tree (faminifera) is one of the most economically useful plants in Africa, the leaves are used for shelter and the stem produces palm sap, which is consumed as a beverage. Physical and mechanical properties of raphia palm kernel were studied at three different moisture content levels of $9.69 \%, 14.69 \%$, and $19.69 \%$ using standard methods and instruments. The physical properties studied were minor, intermediate, major and geometric mean diameters, arithmetic means diameter, surface area, sphericity, aspect ratio, angle of repose, bulk density, and coefficient of static friction. While the mechanical properties were maximum force, bioyield force, and deformation. The result of the physical properties of the kernel determined revealed that major diameter ranged between 42.41-43.43 mm, intermediate diameter ranged between 35.88-36.69 mm, minor diameter ranged between 23.81-25.31 mm, geometric mean diameter ranged between 33.09-34.29 $\mathrm{mm}$, sphericity ranged between 7.80-7.93, surface area ranged between $32.01-34.31 \mathrm{~cm}^{2}$, true density ranged between $1.17-1.50 \mathrm{~g} / \mathrm{mm}^{3}$, bulk density ranged between $0.8-1.19 \mathrm{~g} /$ $\mathrm{mm}^{3}$, porosity ranged between $31.62-42.18 \%$, angle of repose ranged between $40.24-$ $42.18^{\circ}$ and coefficient of static friction ranged between $2.55-0.44,0.5-0.14$ on plywood and steel respectively. While the mechanical properties ranged between 11.01-30.06 kN for maximum force, 5.6-12 $\mathrm{kN}$ for bioyield point and 10.55-12.75 mm for deformation on horizontal loading and 9.44-11.77 $\mathrm{kN}$ for maximum force, 4.7-3.8 $\mathrm{kN}$ for bioyield point and 8.1-7.70 $\mathrm{mm}$ deformation on vertical loading. Consequently, the result will provide data for efficient handling and equipment design to the engineer.
\end{abstract}

\section{Introduction}

Raphia palm tree (faminifera) is the largest palm in Africa and is restricted to the tropical rainforest, the ideal ecological condition for the Raphia palm (Fabunmi et al., 2015, Ndon, 2003). Raphia palm tree is a representative of the family of Palmae or Palmacea. There are about thirty species of the tree within the tropical and subtropical regions in the world. In Nigeria, it is represented by about five species: Raphia hookeri Mann and Wendl., Raphia sudanica Chev., Raphia vinifera Beauv., Raphia regalis Beccand Raphia faminifera (Ogbuag, 2008, Oyen and Lammens, 2002, Profizi, 1985). Palms are monocots, included in the section of Angiosperms characterized by bearing a single seed leaf. Technically, palms are classified as belonging to the family Palmae (the alternative name is Arecaceae), are perennial and distinguished by having woody stems.
According to Johnson (2010), the palm family consists of five subfamilies, each representing a major line of evolution. The Calamoideae is the subfamily with the most unspecialized characters. It is followed by the Nypoideae, Coryphoideae, Ceroxyloideae and Arecoideae; subfamilies; the last exhibiting the greatest number of specialized characters. The foregoing names are based on the genus originally thought to be most characteristic of each subfamily, all of which have species of economic importance. These are the rattan palm (Calamus), nipa palm (Nypa), talipot palm (Corypha), Andean wax palm (Ceroxylon) and betel nut $\operatorname{palm}($ Areca).

Economically, Savanna Palm trees are very important. For example, these trees are sources of wood, fuel, fodder, while some play prominent roles in nutrient recycling and in agro-forestry practices. The sap of many 
species like Hyphaene, Phoenix, Cocos etc., yielded sugar and palm wine (about 500-1212 liters per annum) (Burkill, 1997; Ndon, 2003). Fibers gained from leaves are woven into mats, ropes, fans, bags, baskets, fish traps and other domestic utensils while the stem is used for planks (Connelly and Wilson, 2001). Succulent, oily larvae of weevils and beetles are obtained from infected palms and serve as a delicacy, (Ewuim et al., 2011).

The fibre is produced from the membrane on the underside of each individual frond leaf. The membrane is taken off to create a long thin fibre which can be dyed and woven as a textile into products ranging from hats to shoes to decorative mats. Palm raphia fibres are exported and used as garden ties or as a natural string in many countries. Especially when one wishes to graft trees, raphia is used to hold plant parts together as a more natural rope. Raphia fibres have many uses, especially in the area of textile and in construction. In their local environments, they are used for ropes, sticks and supporting beams, and various roof coverings are made out of its fibrous branches and leaves.

Raffia oil is very similar to palm oil in chemical composition and is used for cooking, as liniment, as lubricant, for lighting and in cosmetics and could be used for making soap and margarine (Akpan and Usoh, 2004). The mesocarp of the ripe fruit yields an edible oil (Ohimain et al., 2013).

The decrease of oil reserves and increased awareness of the pollution caused by the use of synthetic fibers has generated interest in natural fibers, which are renewable and biodegradable resources. For economic reasons, most of the studies performed on these fibers are concerned mainly with plants produced industrially (e.g., flax, hemp, jute, sisal, and ramie) in Europe and Asia.

Along with the intensively exploited so-called tropical wood family, inter-tropical forests possess many underexploited renewable resources, such as raw biodegradable fibers. Among these resources, the raphia palm tree belongs to the multifunctional plant family. For instance, from its nuts, edible and cosmetic oils are extracted. The petioles and raw leaves are used as construction materials, and the raw fibers are extracted from the upper surface of the leaflets. These fibers are traditionally used for making intricate dresses, carpets (Kasai velvet), blankets and objects of art, while elsewhere (particularly in Europe) they are used as ligatures for grafting. Today, they are also used in the manufacture of clothes, shoes, handbags, etc. The flower is signaled by the simultaneous appearance in the crown of more than one expanded spear leaves. It is usually at this stage that the palm is tapped for sap/wine (Obahiagbon, 2009).
In farm structures and design of processing machinery for agricultural bio-materials, knowledge of basic properties of these bio-materials are required (Omobuwajo et al., 1991; Waziri and Mittal, 1997). Therefore, this paper focuses on the determination of some engineering properties of Raphia Palm Kernel at different moisture contents.

\section{Materials and methods}

\subsection{Sample Preparation}

The kernel seeds of Raphia faminifera variety were removed from bunches and boiled to remove the epicarp, mesocarp and endocarp were separated, washed and air dried as shown in Figure 1.

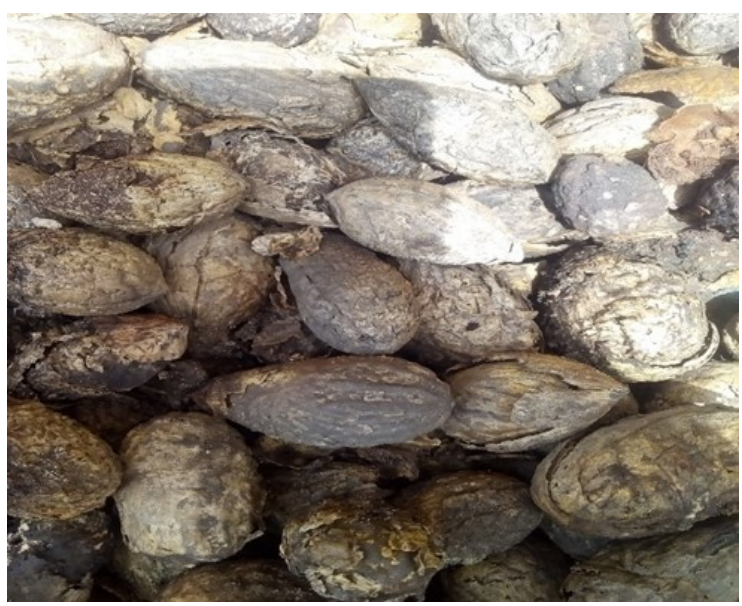

Figure 1. Raphia palm kernel

The initial moisture content of the raphia palm kernel was determined using the ASAE standard S 352.2 involving the use of oven drying method (ASAE). The samples were prepared to the desired moisture contents of $9.69 \%, 14.69 \%$, and $19.69 \%$ by adding the calculated amount of distilled water and kept in separate lowdensity polyethylene bags. The samples were kept in a Revco Deep Freezer with model number A45605C at a temperature of $5 \pm 1{ }^{\circ} \mathrm{C}$ for a period of ten hours. For each test, the required quantity of the kernels was taken out and allowed to attain room temperature for one hour before it was used. The amount of moisture added was calculated by the expression shown in Equation (1).

$M_{w}=\frac{W_{s}\left(M_{f}-M i\right)}{100-M_{f}}$

Where $\mathrm{M}_{\mathrm{i}}=$ Initial moisture content of raphia palm kernel $(\mathrm{g}) ; \mathrm{M}_{\mathrm{f}}=$ Final moisture content of raphia palm kernel $(\mathrm{g}) ; \mathrm{W}_{\mathrm{s}}=$ Weight of the sample $(\mathrm{g})$; and $\mathrm{M}_{\mathrm{w}}=$ Mass of water added $(\mathrm{g})$

\subsection{Measurement of length, width and thickness}

One hundred raphia palm kernels were randomly selected for each of the moisture content considered and labeled for easy identification. The three principal dimensions namely the length, width, and thickness were 
measured with a Mitutoyo absolute digimatic vernier calliper (precision 0.010) (Dauda et al., 2014; Dauda et al., 2015).

\subsection{Geometric mean diameter}

The geometric mean diameter, $\mathrm{D}_{\mathrm{g}}$, of the kernel was calculated by using the following relationship in Equation (2) (Balami et al., 2014; Balami et al., 2016; Mohammed et al., 2017).

$D_{g}=(a b c)^{1 / 3}$

Where $a=$ major diameter $(\mathrm{mm}) ; b=$ intermediate diameter $(\mathrm{mm})$; and $c=$ minor diameter $(\mathrm{mm})$.

\subsection{Sphericity}

The sphericity of Raphia palm kernel was calculated by using the following relationship (Balami et al., 2016) in Equation (3).

Sphericity $=\frac{\text { Geometric mean diameter }}{\text { Major diameter }}=\frac{(a b c)^{\frac{1}{3}}}{a}$

Where $a=$ major diameter $(\mathrm{mm}) ; b=$ intermediate diameter $(\mathrm{mm})$; and $c=$ minor diameter, $(\mathrm{mm})$.

\subsection{Hundred Kernel Mass Determination}

Hundred kernel weight was obtained by using the digital weighing balance of $0.01 \mathrm{~g}$ accuracy.

\subsection{Measurement of volume and true density}

The kernel volume $\left(\mathrm{V}_{\mathrm{s} .}\right)$ and true density $\left(\mathrm{p}_{\mathrm{t} .}\right)$, as a function of moisture content, was determined by toluene displacement method (Shahi et al., 2012). The amount of displaced toluene was determined by hanging a bunch of thirty seeds in a graduated measuring cylinder. Prior to immersion in toluene, they were coated with a very thin layer of epoxy resin adhesive (Araldite) to avoid any absorption of toluene during the experiment.

\subsection{Bulk density determination}

The bulk density $(P b)$ of these kernels was determined by pouring the kernels into a container of $250 \mathrm{~mL}$ from a height of $15 \mathrm{~cm}$ and the excess seeds were removed by a strike-off stick. The content was weighed with a digital weighing balance, Model MT 2000 (Gibertini Electronic, Italy) having a sensitive of $0.01 \mathrm{~g}$ and divided by the volume of the container.

\subsection{Porosity}

Porosity $\left(\mathrm{p}_{\mathrm{f}}\right)$ of the bulk kernel was determined from the values of the true density and bulk density of the raphia palm kernel by using the relationship shown in Equation (4) (Shahi et al., 2012). $p_{f=\left(1-\frac{p_{b}}{p_{t}}\right) \times 100}$

Where $p_{\mathrm{f}}=$ porosity; $p_{\mathrm{t}}=$ true density $\left(\mathrm{g} / \mathrm{mm}^{3}\right)$; and $p_{\mathrm{b}}=$ bulk density $\left(\mathrm{g} / \mathrm{mm}^{3}\right)$

\subsection{Angle of repose}

Angle of repose of the bulk material was measured by the use of an improvised method. The kernels were poured into an opened cylindrical can placed on a smooth-flat surface until it was filled to the brim. The cylindrical can was hence gradually lifted up allowing a gentle flow of the kernels downwards so that the bulk kernel forms a cone-shaped pile. However, with the help of adjustable pointer and scale rule, the angle of repose was hence determined, using the relationship below in Equations (5) and (6):

$$
\begin{aligned}
& \text { Tangent }=\frac{\text { opposite }}{\text { adjacent }} \\
& \theta r=\tan ^{-1}\left(\frac{\text { opposite }}{\text { adjacent }}\right)
\end{aligned}
$$

Where $\theta r=$ Angle of repose; opposite $=$ height of the piled kernel $(\mathrm{m})$; and adjacent $=$ radius of the opened can (m).

\subsection{Determination of surface area}

The surface area was determined by first coating the surface of the kernel with paints and folded with a light sensitive paper (void paper). The surface edge was traced out with a very sharp thin pencil on a graph paper. The surface area was measured by counting the number of squares with the traced marks and the square that was at least half was also covered (Chukwu and Sunmonu, 2010).

\subsection{Coefficient of friction}

The coefficient of static friction of raphia kernel was determined on three different surfaces (plywood, glass and mild steel) for all the three samples. It was determined by filling a hollow plastic box with kernels. The box was placed on the surface, which was gradually tilted until the box just began to slide down the surface. The angle the surface made with the horizontal was taken. The coefficient of friction $(\mu)$ was obtained by finding the tangent of the angle with the relationship in Equation (7) (Olajide and Igbeka, 2003).

$$
\mu=\tan \beta
$$

Where $\mu=$ Static coefficient of friction; and $\beta=$ angle of inclination

\subsection{Mechanical properties of raphia palm kernel}

The test on the mechanical properties of raphia palm was carried out at Federal Polytechnic Bida, Niger state. The compressive test was conducted using an Electronic 
Controlled Universal Testing machine model WDW 50 with maximum load capacity 50N (Figure 2).

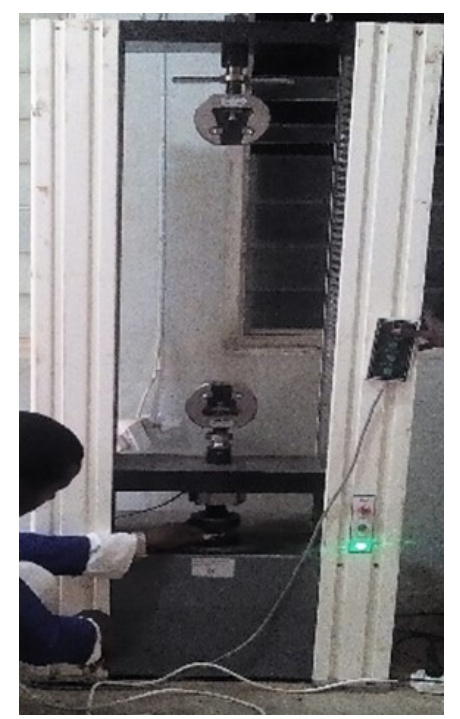

Figure 2. Electronic Controlled Universal Testing machine model WDW 50.

Prior to the test, the raphia palm samples were identified according to their moisture levels and labelled as $\mathrm{A}, \mathrm{B}$, and $\mathrm{C}$ signifying moisture contents $\mathrm{x} \%, \mathrm{y} \%$ and $\mathrm{Z} \%$ respectively.

The samples were labelled so that they can be loaded vertically and horizontally at each moisture level, while each test repeated twice. For example, a sample assigned an ID RPAH1 signifies Raphia palm sample 1 at moisture level A\%, loaded horizontally. Within samples fully prepared, the universal testing machine was then powered on starting with computer unit. The computer control of the testing machine was done using a software. Maximum Test on the test console of the Max Test respective sample IDs was entered and load displacement was set to $5 \mathrm{~mm} / \mathrm{min}$ after the sample was securely fixed on the compressive strength test unit of the machine; while the graphical output was set to force deformation plot. The sample was then loaded while the graph being plotted was observed on the screen until the sample was completely ruptured. Following the (ASAE), 1998, bio-yield and rupture (breaking) points for each sample were obtained from the graph.

\section{Results and discussion}

The results obtained for the physical and mechanical properties studied at the three different moisture contents levels are shown in Tables 1 and 2.

It can be seen from Table 1 that the values of the physical properties of the kernel obtained shows that the major diameter was ranging between $42.41-43.43 \mathrm{~mm}$, intermediate diameter was between $35.88-36.69 \mathrm{~mm}$, minor diameter was between $23.81-25.31 \mathrm{~mm}$, geometric mean diameter was between $33.09-34.29 \mathrm{~mm}$, sphericity was between 7.80-7.93, surface area was between 32.01$34.31 \mathrm{~cm}^{2}$, true density was between $1.17-1.50 \mathrm{~g} / \mathrm{mm}^{3}$, bulk density was between $0.8-1.19 \mathrm{~g} / \mathrm{mm}^{3}$, porosity was between $31.62-42.18 \%$, angle of repose was between $40.24-42.18^{\circ}$ and coefficient of static friction was between 2.55-0.44, 0.5-0.14 on plywood and steel respectively.

The axial dimension of raphia palm kernel, including the major diameter, intermediate diameter and the minor diameter at different moisture contents of $9.69 \%, 14.69 \%$ and $19.69 \%$ are shown in Figures 3a, 3b, and 3c). It was observed that the major diameter, intermediate diameter and the minor diameter increased with increase in moisture content (Figures 3a, 3b, and 3c).

The geometric mean diameter was significantly correlated to moisture content of raphia palm kernel. The geometric mean diameter increased as moisture content increased as shown in Figure 4. The increase in the value may be attributed to its dependence on the three principal dimensions of the raphia palm kernel. The geometric mean diameter increased from $0.010 \mathrm{~mm}$ to $0.011 \mathrm{~mm}$ with an increase in moisture content. This result was similar to the result obtained by Bamgboye and Adejumo (2009) for roselle seeds.

The sphericity of raphia palm kernel did not depend on the moisture content of the raphia palm kernel as shown in Figure 5. There was no change in sphericity with increase in moisture content. Although this result was not the same as the result obtained for Iranian melon seeds of Koocheki et al. (2007), obtained an increase in Sphericity as moisture content increased. This result shows that physical properties of raphia palm kernel not only dependent on the moisture content but also on the area of cultivation. Figure 5 shows the behaviour of sphericity of raphia palm kernel with respect to increase in moisture content.

Bulk density and True density of raphia palm kernel increased with increase in moisture content. Bulk density and true density also varied from 0.8 to $1.19 \mathrm{~g} / \mathrm{mm}^{3} 1.17$ to $1.50 \mathrm{~g} / \mathrm{mm}^{3}$ as moisture content increased from $9.69 \%$ to $19.69 \%$ respectively. Both bulk density and true density were not well correlated with an increase in moisture content. Figures $6 \mathrm{a}$ and $\mathrm{b}$ shows the nonlinear relationship between bulk density, true density with increase in moisture content.

The porosity of raphia palm kernel decreased as moisture content increased. Porosity depended on true density of raphia palm kernel, the higher the true density the higher the porosity. A similar trend was reported by Koocheki et al. (2007) for the three Iranian varieties of melon seeds. Figure 7 shows the relationship between 
Table 1. Physical properties of raphia palm seeds at three different moisture content levels

\begin{tabular}{lccc}
\hline Properties & $9.69 \%$ & $14.69 \%$ & $19.69 \%$ \\
\hline Major diameter $(\mathrm{mm})$ & $42.414 \pm 0.0059$ & $42.915 \pm 0.0059$ & $43.438 \pm 0.0064$ \\
Intermediate Diameter $(\mathrm{mm})$ & $35.884 \pm 0.0041$ & $36.101 \pm 0.0041$ & $36.694 \pm 0.0046$ \\
Minor Diameter $(\mathrm{mm})$ & $23.811 \pm 0.0027$ & $24.324 \pm 0.0028$ & $25.310 \pm 0.0029$ \\
Geometric Mean Diameter $(\mathrm{mm})$ & $33.092 \pm 0.0040$ & $33.526 \pm 0.0041$ & $34.297 \pm 0.0047$ \\
Sphericity & $7.802 \pm 0.00095$ & $7.812 \pm 0.00095$ & $7.934 \pm 0.00098$ \\
Surface Area $\left(\mathrm{cm}^{2}\right)$ & $32.01 \pm 0.0061$ & $33.11 \pm 0.0062$ & $34.31 \pm 0.0063$ \\
True Density $\left(\mathrm{g} / \mathrm{mm}^{3}\right)$ & $1.17 \pm 0.042$ & $1.28 \pm 0.042$ & $1.50 \pm 0.042$ \\
Bulk Density $\left(\mathrm{g} / \mathrm{mm}^{3}\right)$ & $0.8 \pm 0.035$ & $1.01 \pm 0.036$ & $1.19 \pm 0.035$ \\
Porosity $(\%)$ & $31.624 \pm 0.15$ & $21.09 \pm 0.016$ & $20.67 \pm 0.016$ \\
Angle of Repose $\left({ }^{\circ}\right)$ & $40.24 \pm 0.0011$ & $41.35 \pm 0.0010$ & $42.18 \pm 0.0012$ \\
Coefficient of Static Friction & & & \\
Plywood & $2.55 \pm 0.0011$ & $0.34 \pm 0.0010$ & $0.44 \pm 0.0012$ \\
Steel & $0.50 \pm 0.0089$ & $1.58 \pm 0.0078$ & $0.14 \pm 0.0091$ \\
Glass & & $0.14 \pm 0.0073$ & $0.32 \pm 0.0069$ \\
\hline
\end{tabular}

Table 2. Mechanical properties of raphia palm seeds at three different moisture content levels

\begin{tabular}{lccc}
\hline Properties & $9.69 \%$ & $14.69 \%$ & $19.69 \%$ \\
\hline \multicolumn{4}{c}{ Horizontal Loading } \\
\hline Maximum Force $(\mathrm{kN})$ & $30.06 \pm 10.63$ & $16.23 \pm 5.88$ & $11.01 \pm 6.94$ \\
Bioyield point $(\mathrm{kN})$ & $12 \pm 4.38$ & $6.5 \pm 2.37$ & $5.6 \pm 2.76$ \\
Deformation $(\mathrm{mm})$ & $12.75 \pm 4.51$ & $11 \pm 4.60$ & $10.55 \pm 3.73$ \\
\hline \multicolumn{5}{c}{} \\
\hline Maximum Force $(\mathrm{kN})$ & Vertical Loading & $15.54 \pm 5.51$ & $9.44 \pm 3.34$ \\
Bio-yield point $(\mathrm{kN})$ & $11.77 \pm 4.17$ & $6.2 \pm 2.33$ & $3.8 \pm 2.19$ \\
Deformation $(\mathrm{mm})$ & $4.7 \pm 1.8$ & $11 \pm 3.10$ & $7.7 \pm 3.75$ \\
\hline
\end{tabular}

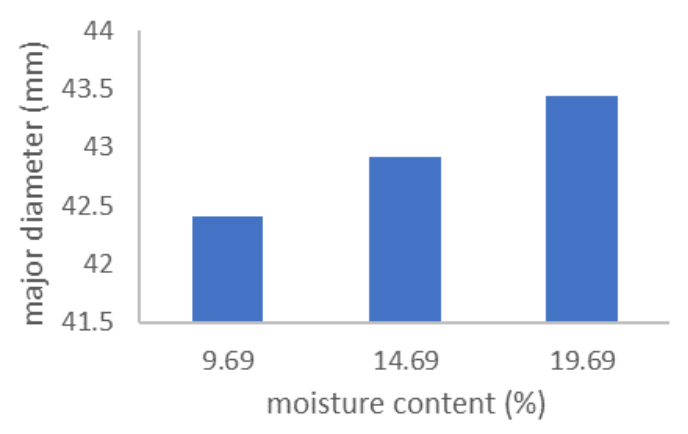

Figure 3a. Effect of moisture content on major diameter

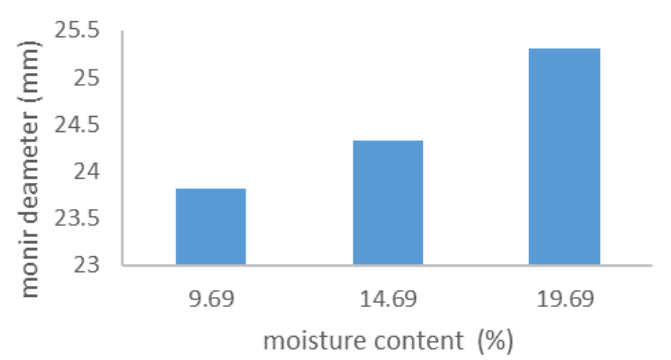

Figure 3c. Effect of moisture content on minor diameter

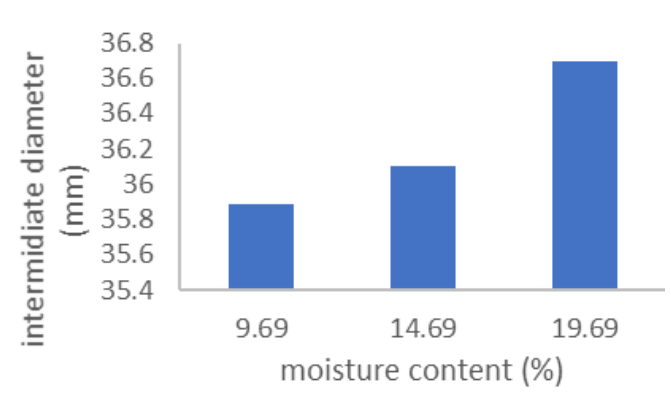

Figure 3b. Effect of moisture content on intermediate diameter

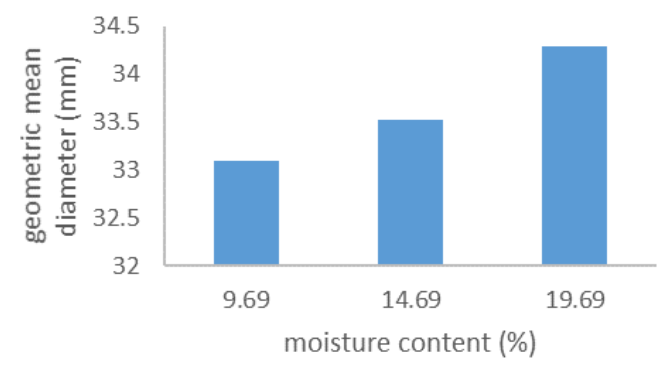

Figure 4. Effect of moisture content on geometric mean diameter

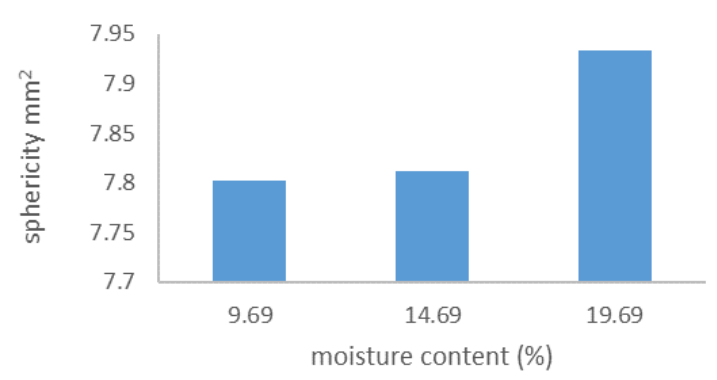

Figure 5. Effect of moisture content on sphericity 


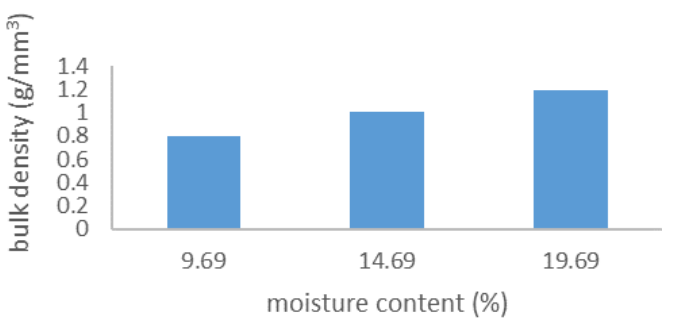

Figure 6a. Effect of moisture content on bulk density

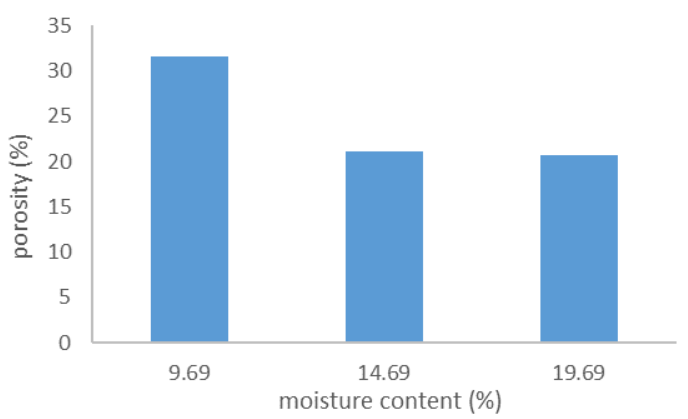

Figure 7. Effect of moisture content on porosity

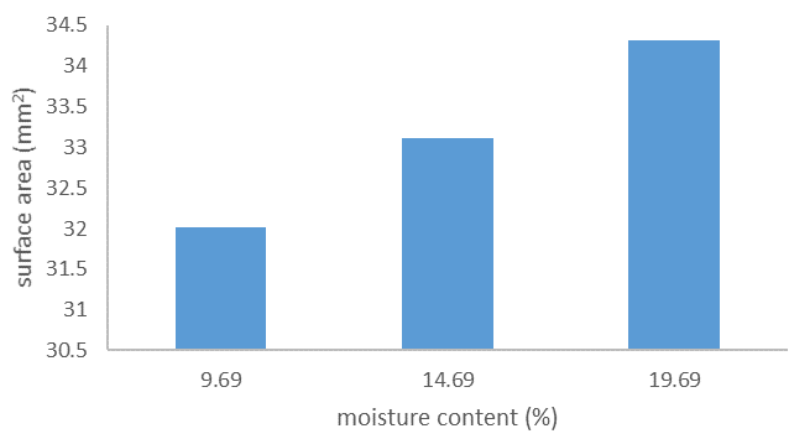

Figure 9. Effect of moisture content on surface area

moisture content and porosity.

The angle of repose of raphia palm kernel increased with increase in moisture content. The value for the angle of repose was $40.24^{\circ}, 41.35^{\circ}$ and $42.18^{\circ}$ for raphia palm kernel at $9.69 \%, 14.69 \%$ and $19.69 \%$ moisture content respectively. There was a linear increase in the angle of repose with the increase in moisture content. These results were similar to the angle of repose of roselle seed as reported by Bangboye and Adejumo (2009) which shows the linear increase in angle of repose with increase in moisture content from $20.13^{\circ}$ to $24.85^{\circ}$. The angle of repose of raphia palm kernel correlated well with the increase in moisture content as shown in Figure 8.

It was observed that the static coefficient of friction increased with increase in moisture content for all the three surfaces (glass, plywood, galvanized mild sheet) tested. A similar observation was reported for millet (Baryeh, 2002). It was also observed that the static coefficient of friction of raphia palm kernel did not only increase with an increase in moisture content but also depends on porosity (Figure 9). Raphia palm kernel with $9.69 \%$ moisture content had the highest porosity and also the highest static coefficient of friction on the glass

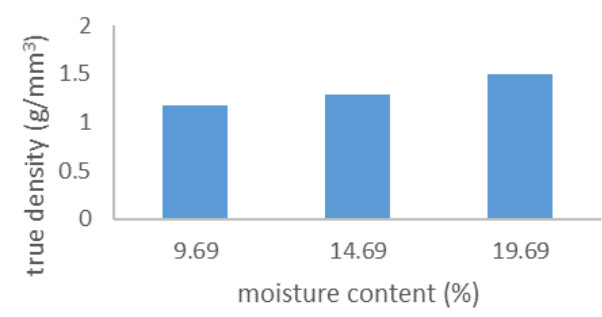

Figure $6 \mathrm{~b}$. Effect of moisture content on true density

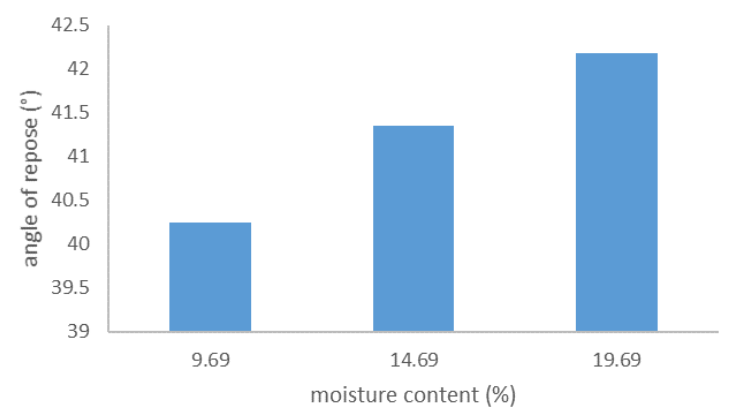

Figure 8. Effect of moisture content on angle of repose

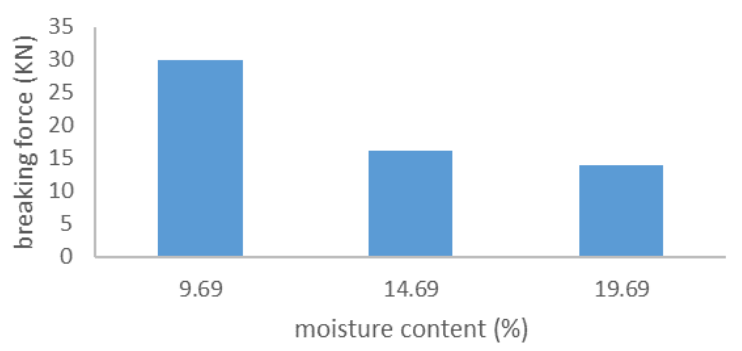

Figure 10. Effect of moisture content on breaking force

surface and galvanized mild sheet surface. This may be due to ease at which moisture distributed through highly porous raphia palm kernel. But on wood surface, raphia palm kernel of $19.69 \%$ moisture content had the highest static coefficient of friction of 0.44 .

Surface area not only increased with increase in moisture content, but surface area also increased as a function of length and width. Raphia palm kernel with $19.69 \%$ moisture content had the highest length and width followed by raphia palm kernel with $14.69 \%$. This trend also was reflected on their surface area as raphia palm kernel with $19.69 \%$ moisture content had the highest surface area followed by with $14.69 \%$ and 9.69 respectively moisture content. Their surface area values were $34.31 \mathrm{~mm}^{2}, 33.11 \mathrm{~mm}^{2}$ and $32.01 \mathrm{~mm}^{2}$ for raphia palm kernel at $19.69 \%, 14.69 \%$, and $9.69 \%$ moisture contents respectively.

The following mechanical properties were obtained from the test results as presented in Table 2 the breaking force, bioyield point and the deformation.

From Table 2, the mechanical properties of raphia palm kernel on horizontal and vertical loading at three different moisture content of $9.6 \%, 14.69 \%$ and $19.69 \%$. 
The result on horizontal loading indicates a mean maximum force of $30.06 \mathrm{kN}, 16.23 \mathrm{kN}$, and $11.01 \mathrm{kN}$, the Bioyield point is $12 \mathrm{kN}, 6.5 \mathrm{kN}$ and $5.6 \mathrm{kN}$ while deformation is $12.75 \mathrm{~mm}, 11.0 \mathrm{~mm}$ and $10.55 \mathrm{~mm}$ each at $9.69 \%, \quad 14.69 \%$ and $19.69 \%$ moisture content respectively. This indicates that mechanical properties studied decreases with increasing moisture content. Furthermore, on vertical loading, maximum forces were $11.77 \mathrm{kN}, 15.4 \mathrm{kN}$ and $9.44 \mathrm{kN}$, the bioyield point were $4.7 \mathrm{kN} 6.2 \mathrm{kN}$ and $3.8 \mathrm{kN}$ while deformations were 8.1 $\mathrm{mm}, 11.0 \mathrm{~mm}$ and $7.7 \mathrm{~mm}$ each at $9.69 \%, 14.69 \%$ and $19.69 \%$ respectively. This indicates a relatively higher value in mechanical properties determined at $14.69 \%$ moisture content on vertical loading.

Figure 10 also shows that the breaking force of raphia palm kernel decreased with the increase in moisture contents from $9.69 \%, 14.69 \%$ and $19.69 \%$ respectively.

This study showed that the higher force was required for deformation of raphia palm kernel at low moisture content and also showed that raphia palm kernel could resist higher stress when it was placed horizontally under applied load than when it was placed vertically. These values are important for the design of crushing and milling machine especially for crop processing which further implied a fundamental knowledge of agricultural behaviour whereby under mechanical forces the biomaterial can resist and is very essential in determining the power requirement for different operations such as cutting, crushing pressing milling.

\section{Conclusion}

Based on this study it can be concluded that as the moisture content varied from $9.69 \%$ to $14.69 \%$ and $19.69 \%$ the linear dimensions of arithmetic mean diameter, geometric diameter, surface area, sphericity, aspect ratio and angle of repose, increased with increase in moisture content. The results from this study also helped us to know that at higher moisture content,-the sample breaks faster. Moisture content was observed to have an influence on the compressive strength of raphia palm kernel.

\section{References}

Akpan, E.J. and Usoh, I.F. (2004). Phytochemical screening and effect of aqueous root extract of Raphia hookeri (raffia palm) on metabolic clearance rate of ethanol in rabbits. Biokemistri, 16(1), 37-42.

Balami, A.A., Aliyu, M., Dauda, S.M. and Peter. O. (2014). Physical properties of neem (Azadirachta indica) seeds and kernels relevant in the design of processing machineries. Arid Zone Journal of
Engineering, Technology and Environment, 10, 5362.

Balami, A.A., Dauda, S.M., Lawal, A. and Ahmad, D. (2016). Some engineering properties of Palmyra palm tree (Borassus aethiopum) germinating shoot. Agricultural Engineering International: CIGR Journal, 18(1), 58-69.

Bamgboye, A.I. and Adejumo, O.I. (2009). Physical Properties of Roselle (Hibiscus Sabdariffa L.) seed. Agricultural Engineering International: the CIGR Ejournal, 11.

Baryeh, E.A. (2002). Physical properties of millet. Journal of Food Engineering, 51(1), 39-46. https:// doi.org/10.1016/S0260-8774(01)00035-8

Burkill, H.M. (1997). Pedaliaceae: The useful plants of West Tropical Africa. 2nd ed. Vol. 4. p. 414-423. Kew: Royal Botanic Gardens.

Chukwu, O. and Sunmonu, M.O. (2010). Determination of Selected Engineering Properties of Cowpea (Vigna unguiculata). Related to Design of Processing Machines. International Journal of Engineering and Technology, 2(6), 373-378.

Connelly, S. and Wilson, N. (2001). Trees for seminomadic farmers: a key to resilience. Leisa Magazine, 17, 10-11. Retrieved from website: https://core.ac.uk/download/pdf/48026100.pdf

Dauda, S.M., Ahmad, D., Khalina, A. and Jamarei, O. (2014). Physical and mechanical properties of kenaf stems at varying moisture contents. Agriculture and Agricultural Science Procedia, 2, 370-374. https:// doi.org/10.1016/j.aaspro.2014.11.051

Dauda, S.M., Ahmad, D., Khalina, A. and Jamarei, O. (2015). Effect of cutting speed on cutting torque and cutting power of varying kenaf-stem diameters at different moisture contents. Pertanika Journal of Tropical Agricultural Science, 38(4), 549-561.

Ewuim, S.C., Akunne, C.E., Anumba, A.I. and Etaga, H.O. (2011). Insects associated with wine from Raffia palm (Raphia Hookeri) in Alor, Nigeria. Animal Research International, 8(1), 1328-1336.

Fabunmi, O.A., Omeiza, U. and Alabadan, B.A. (2015). Physical and Mechanical Properties of Raphia (Raphia farinifera) Seed essential for handling and processing operation. Proceedings of the first International Engineering Conference (IEC), p. 6170. Nigeria: Federal University of Technology

Johnson, D.V. (2010). Non-Wood Forest Products, 10/ Rev. 1 Tropical palms 2010 revision. Rome: FAO.

Koocheki, A., Razavi, S.M.A., Milani, E., Moghadam, T.M., Abedini, M., Alamatiyan, S. and Izadkhah, S. (2007). Physical Properties of Watermelon seed as a function of moisture content and Variety. 
International Agrophysics, 21, 349-359.

Mohammed, A., Balami, A.A., Dauda, S.M., Mohammed, I.S. and Abdulfatai, Y. (2017). Engineering properties of luffa (L. cylindrica) seed relevant to the processing machineries. Agricultural Engineering International: CIGR Journal, 19(3), 47 -55 .

Ndon, B.A. (2003). The Raphia palm (Economic Palm Series), p. 155. Lagos, Nigeria: Concept Publication Limited

Obahiagbon, F.I. (2009). A review of the origin, morphology, cultivation, economic products, health and physiological implications of raphia palm. African Journal of Food Science, 3(13), 447-453.

Ogbuag, M.N. (2008). Vitamins, phytochemicals and toxic elements in the pulp and seed of Raphia palm fruit (Raphia hookeri). Technical paper. Fruits, 63 (5), 297-302.

Ohimain, E.I., Tuwon, P.E. and Ayibaebi, E.A. (2013). Traditional fermentation and distillation of raffia palm sap for the production of bioethanol in Bayelsa State, Nigeria. Journal of Technology Innovations in Renewable Energy, 1(2), 131-141.

Olajide, J.O. and Igbeka, J.C. (2003). Some Physical Properties of Groundnut Kernels. Journal of Food Engineering, 58(2), 201-204. https:// doi.org/10.1016/S0260-8774(02)00323-0

Omobuwajo T.O., Akande E.A. and Sanni, L.A. (1991). Selected physical, mechanical and aerodynamic properties of African breadfruit Tyreculiaa fricana seeds. Journal of Food Engineering, 40(4), 241-244. https://doi.org/10.1016/S0260-8774(99)00060-6

Oyen, L.P.A. and Lemmens, R.H.M.J. (2002). Plant resources of tropical Africa. Precursor. Wageningen, the Netherlands: PROTA Programme.

Profizi, J. P. (1985). Raphia hookeri: a survey of some aspects of the growth of a useful swamp Lepidocaryoid palm in Benin (West Africa). Principes, 29(3), 108-114.

Shahi, N.C., Lohani, U.C., Chand, K. and Singh, A. (2012). Effect of pre-cooling treatments on shelf life of tomato in ambient condition. International Journal of Food, Agriculture and Veterinary Sciences, 2(3), 50-56.

Waziri, A.N. and Mittal, J.P. (1997). Design Related Physical Properties of Selected Agricultural Products. Agricultural Mechanization Assistance, 14 (1), 59-62. 